\title{
Mechanisms of ALA-D inhibition by lead and of its restoration by zinc and dithiothreitol
}

\author{
T SAKAI, S YANAGIHARA, Y KUNUGI, AND K USHIO \\ From the Center of Occupational Medicine, Tokyo Labor Accident Hospital, Ota-Ku, Tokyo 143, Japan
}

\begin{abstract}
To induce the inhibition of ALA-D (delta-aminolaevulinic acid dehydratase) activity by lead in vitro, it is necessary to preincubate the enzyme fraction with lead ions and the $\mathrm{Hb}$ fraction (factors) together. The combination of two of the three (ALA-D fraction, lead acetate, and $\mathrm{Hb}$ fraction) in the preincubation has only a small effect on the activity. Lead preincubated with ALA-D and $\mathrm{Hb}$ fractions does not alter the affinity of the enzyme for the substrate, suggesting that the substrate can bind to the enzyme molecules (non-competitive inhibition). The restoration of activity by zinc with dithiothreitol is associated with the removal of lead from ALA-D fraction proteins to which it has bound in vivo and in vitro. The mode of the inhibitory action of tin on ALA-D is similar to that of lead because the inhibition is intensified by the addition of $\mathrm{Hb}$ fraction and is restored by heating. The inhibition concentration is, however, higher than that of lead. Of the three methods recovering decreased activity, heating is the most specific to detect inhibition by lead.
\end{abstract}

Erythrocyte ALA-D ( $\delta$-aminolaevulinic acid dehydratase) activity is widely used for the evaluation of lead exposure or for the rough estimation of lead in blood that is currently regarded as the most sensitive index of lead exposure. Sakai et $\mathrm{al}^{1}$ have shown that the decrease in ALA-D activity is an indicator of the extent of lead saturation of ALA-D fraction proteins which have the highest affinity for lead among erythrocyte constituents. Nevertheless, the mechanisms of ALA-D inhibition by lead in the fraction have not been elucidated, although some erythrocyte factors are known to be involved in the inhibition. ${ }^{2}$

Depressed ALA-D activity in lead-exposed subjects is restored by heating the enzyme solution ${ }^{34}$ or by adding $\mathrm{SH}$-compounds ${ }^{56}$ or zinc ions ${ }^{78}$ to the reaction mixture. Many workers ${ }^{5-16}$ have tried to evaluate lead exposure, using these agents or procedures recovering the activity. The extent of restoration in activity (activity ratio or VHE) is well correlated with blood lead concentrations, and the correlation is better than that between ALA-D activity itself and blood lead concentrations. This is probably because the normal range of activity ratio is much narrower than that of ALA-D activity itself,

Received 28 January 1982

Accepted 8 March 1982 and that the ratio is independent of some disorders that affect the activity. ${ }^{10}$ Thus the activity ratio has recently received considerable attention as an index of lead exposure. There has been, however, no standardised method of restoring the decreased activity to evaluate lead exposure nor have the mechanisms of the restoration been clarified.

Heavy metals other than lead can also affect ALA-D activity in vivo. Erythrocyte ALA-D activity in man exposed to either cadmium ${ }^{17}$ or methylmercury ${ }^{18}$ is reported to decrease as in exposure to lead. Chiba and Kikuchi ${ }^{19}$ reported that the activity is decreased in an animal experimentally exposed to tin. The activity is well known to be inhibited by many metals in vitro. ${ }^{140-22}$ By contrast, zinc ions injected subcutaneously into an animal temporarily reverses the lead-inhibition of ALA-D activity in vivo. ${ }^{23}{ }^{24}$ Zinc exposure also affects the activity in man to a small extent. ${ }^{25}$ As yet, however, there has been no evidence to show whether the lead effect on ALA-D activity differs from that of other inhibitory metals as regards the restoration of activity by the above-mentioned agents. If it were so, the mechanisms of the inhibition by lead should differ from those of other metals, and the restoration index (activity ratio) would be more specific and helpful than the activity determination itself in the evaluation of lead exposure.

The purpose of the present study was, therefore, 
to disclose the mechanisms of ALA-D inhibition by lead and of its restoration by some agents, and to clarify the difference between the inhibition of ALA-D activity by lead and that of other heavy metals.

\section{Materials and methods}

Heparinised venous blood was obtained from workers occupationally exposed to lead and from normal subjects with no history of exposure to lead.

Preparation of the $\mathrm{Hb}$ and ALA-D fractions from normal blood was carried out by the method described previously. ${ }^{2}$ Erythrocyte supernatant was gel-filtrated by passing through a Sephadex G-200 column $(2.6 \times 90 \mathrm{~cm})$. Peak fractions with ALA-D activity and with absorption by $\mathrm{Hb}$ were pooled separately and used for the experiments. ALA-D activity was determined by the method of Sakai $e t$ $a l .^{2}$ The methods of inducing ALA-D inhibition by metal ions and of restoring the inhibition were also carried out as described previously. ${ }^{2}$

In the experiment in which the effect of zinc and dithiothreitol (DTT) was examined on the distribution of lead and zinc in erythrocytes, $10 \mathrm{ml}$ of erythrocyte lysate that had been adjusted to the original haematocrit value with $40 \mathrm{mM}$ Tris- $\mathrm{HCl}$ buffer $\mathrm{pH}$ 7.0 were added to $1 \mathrm{ml}$ of the solution containing 5 $\mathrm{mM}$ zinc acetate and $250 \mathrm{mM}$ DTT. The lysate was incubated at $4^{\circ} \mathrm{C}$ for 40 hours and then centrifuged at $24000 \mathrm{~g}$ for 30 minutes. Ten millilitres of the supernatant were passed through a Bio Gel A $5 \mathrm{M}$ column $(2.6 \times 90 \mathrm{~cm})$ that had been equilibrated with $40 \mathrm{mM}$ Tris- $\mathrm{HCl}$ buffer $\mathrm{pH} 7 \cdot 0$. Each fraction was collected in 13- $\mathrm{ml}$ aliquots and subjected to determinations of protein and lead concentrations and of ALA-D activity by the method previously reported.' Zinc concentrations were determined in the same MIBK (methyl-isobutylketone) extract as used to determine lead concentrations, using a flame atomic absorption spectrometer.

With or without zinc and DTT treatment, the erythrocyte supernatant from a lead worker was also gel-filtrated through a Sephadex G-75 column (1.6 $\times 90 \mathrm{~cm}$ ) that had been equilibrated with $40 \mathrm{mM}$ Tris- $\mathrm{HCl}$ buffer $\mathrm{pH} 7 \cdot 0$. ALA-D activity and protein concentrations in the fractions were determined in the manner described above, and lead concentrations in the fractions were directly determined by the method previously reported, using a ffameless atomic absorption spectrometer. ${ }^{1}$

\section{Results}

We have reported that to induce ALA-D inhibition by lead in vitro it is necessary for the enzyme solu-

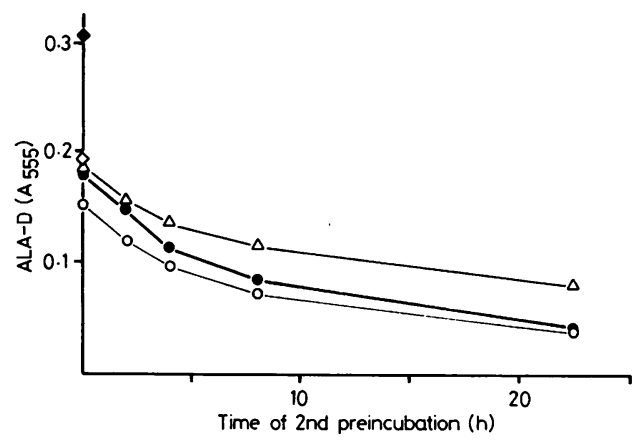

Fig 1 Effect of preincubation of enzyme solution $(E)$ or factors $(F)$ with lead acetate $(P b, 50 \mathrm{nM})$ on inhibition of $A L A-D$ activity. After first preincubation $\left(4^{\circ} \mathrm{C}, 20\right.$ hours $)$ of $P b+F(O)$ or of $E+P b(O)$, the third factor ( $E$ and $F$, respectively) was added and further preincubated at $4^{\circ} \mathrm{C}$ for described time (second preincubation). Control $(\triangle)$ was subjected only to second preincubation in combination of $E$, $P b$, and $F$ together. $\bullet$ : Enzyme solution alone (without $F$ and $P b$ ), $\diamond: E+F$ (without $P b$ ).

tion to be preincubated with lead acetate and the erythrocyte factors in the $\mathrm{Hb}$ fraction. ${ }^{2}$ Figure 1 shows the effect of the preincubation of the enzyme solution (E, ALA-D fraction) or of the $\mathrm{Hb}$ fraction (F) with lead acetate $(\mathrm{Pb})$ on the inhibition of ALA-D. After the first preincubation of lead with either $\mathrm{E}$ or $\mathrm{F}$ for 20 hours at $4^{\circ} \mathrm{C}$, the third factor was added and the mixture further preincubated at $4^{\circ} \mathrm{C}$ for 0 to 23 hours (second preincubation). ALA-D activity was assayed in the final combination. None of the combinations first preincubated $\left(4^{\circ} \mathrm{C}, 20\right.$ hours $)$ induced the pronounced inhibition of ALA-D activity observed when the third factor was introduced. With increasing time of second preincubation, however, the extent of ALA-D inhibition is intensified significantly. At 23 hours of the second preincubation, the extent of ALA-D inhibition first preincubated with lead is almost identical to that observed when the $\mathrm{Hb}$ fraction is first preincubated with lead. These observations indicate that the second preincubation, where the three components are incubated together, is essential to induce the inhibition. Because a long preincubation time is necessary for the enzyme to be inhibited by lead in vitro, it seems that a ternary complex of $E$, $\mathrm{Pb}$, and $\mathrm{F}$ is formed during the preincubation.

Table 1 indicates the extent of lead inhibition of ALA-D in the presence or absence of the $\mathrm{Hb}$ fraction. The Vmax value and the $\mathrm{Km}$ for substrate are determined from double reciprocal plots for the enzyme from Sephadex G-200 gel filtration of normal erythrocyte supernatant. In the absence of the $\mathrm{Hb}$ fraction, $50 \mathrm{nM}$ lead acetate does not inhibit the activity of ALA-D, while $1 \mu \mathrm{M}$ lead inhibits $30 \%$ of 
Table $1 A L A-D$ inhibition by lead in the presence or absence of $H b$ fraction

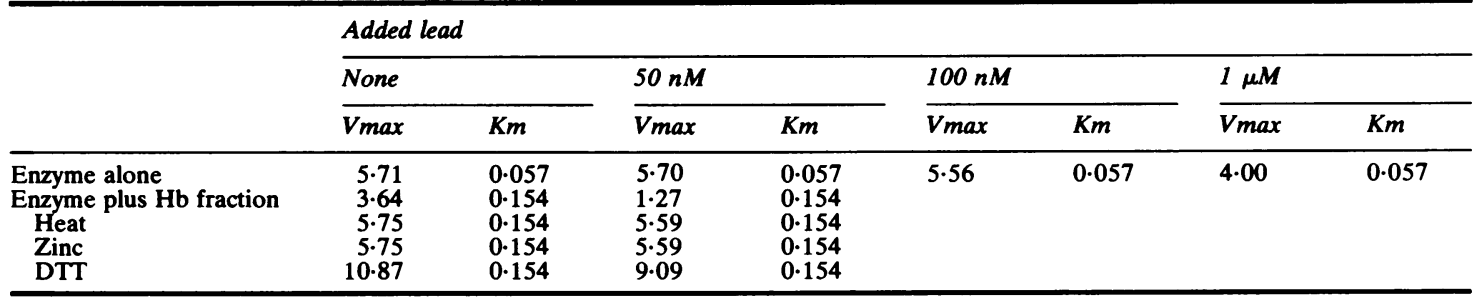

Vmax $(\mu \mathrm{moles} / \mathrm{min} / 1), \mathrm{Km}(\mathrm{mM})$, heat $\left(60^{\circ} \mathrm{C}, 5 \mathrm{~min}\right)$, zinc $(100 \mu \mathrm{M})$, and DTT $(10 \mathrm{mM})$.
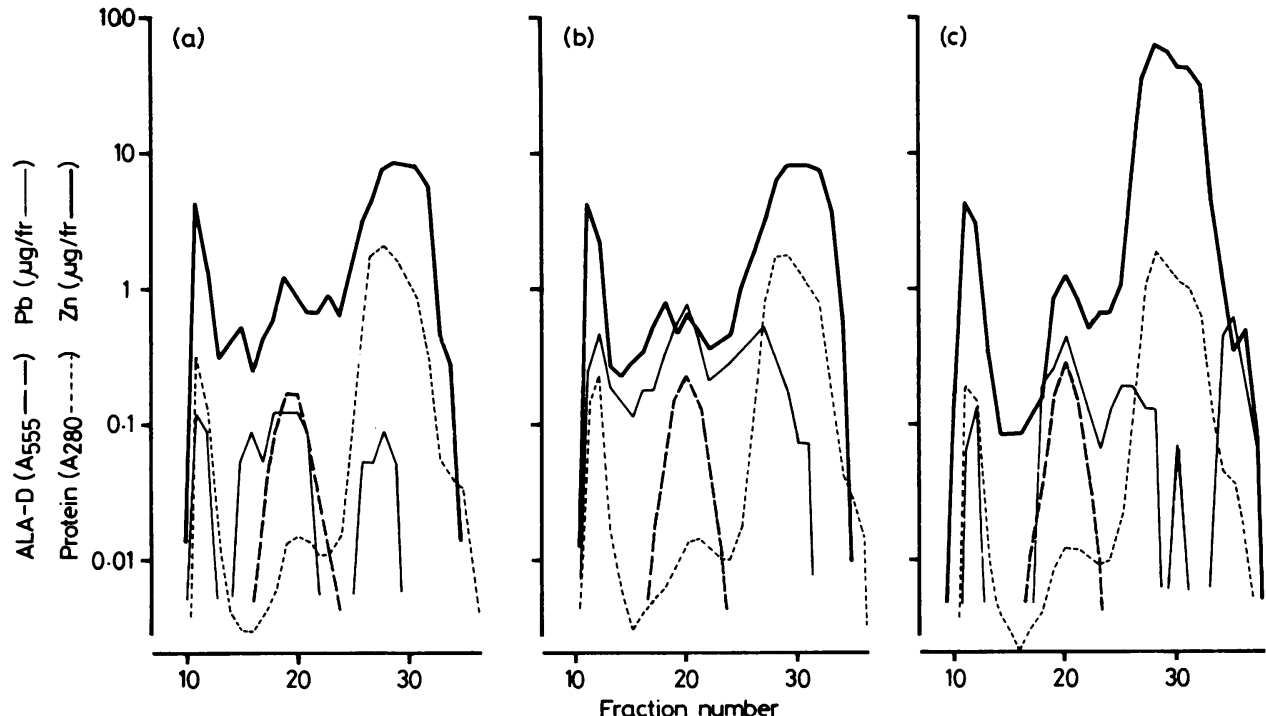

Fig 2 Gel filtration chromatography of erythrocyte zinc and lead. (a): normal subject, (b) and (c): lead-exposed subjects. Before application on to column, erythrocyte lysate from a lead-exposed subject (c) was incubated with zinc and DTT to recover $A L A-D$ activity as described in materials and methods. Blood lead concentrations and ALA-D activity of the three subjects are indicated in table 2.

the activity. The inhibition is non-competitive in type. Both Vmax and $\mathrm{Km}$ are altered by the addition of the $\mathrm{Hb}$ fraction to the mixture. The percentage of inhibition of the $\mathrm{Hb}$ fraction alone is $36 \%$, and the type of inhibition is complex. In the presence of the $\mathrm{Hb}$ fraction, $50 \mathrm{nM}$ lead acetate inhibits the activity significantly $(65 \cdot 1 \%)$. Thus the presence of the $\mathrm{Hb}$ fraction intensifies the inhibition of ALA-D by lead. The type of inhibition is non-competitive, indicating that the substrate can bind to the enzyme molecules. Heat treatment $\left(60^{\circ} \mathrm{C}, 5 \mathrm{~min}\right)$, zinc $(100 \mu \mathrm{M})$, and DTT $(10 \mathrm{mM})$ restore the non-competitive inhibition.

Figure 2 shows the chromatographic pattern of gel filtration of erythrocyte lead and zinc. There is little difference in the distribution pattern of erythrocyte zinc between normal and lead-exposed subjects, while lead peaks in the latter are higher than those in the former. ${ }^{1}$ In the erythrocyte lysate incubated with zinc and DTT before the application on a column (fig 2(c)), a large quantity of lead appears in the peak with low molecular weight-that is, not found in non-treated erythrocytes (fig 2(b))-whereas the amount of lead in the other peaks decreases. Most of zinc added to lysate with DTT is found in the $\mathrm{Hb}$ fractions after gel filtration. Normal erythrocyte lysate that had been incubated with lead acetate to induce the inhibition of ALA-D was also chromatographed with or without the addition of zinc and DTT (fig 3). When zinc and DTT are present, lead bound to the proteins with high molecular weight, including ALA-D, is removed and appears in the low molecular weight fractions. The removal of lead from ALA-D fraction proteins to which it 


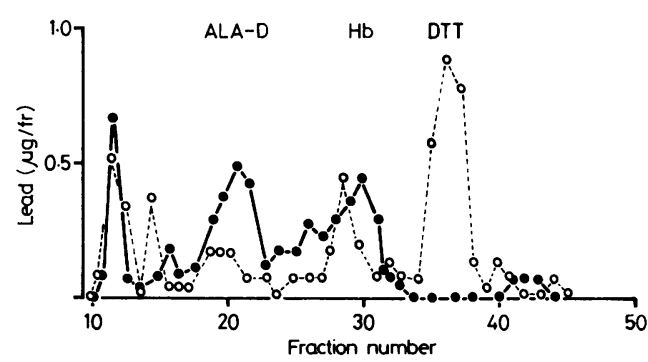

Fig 3 Gel filtration chromatography of erythrocyte lead loaded in vitro, with or without treatment with zinc and DTT. Erythocyte lysate from a normal subject (blood lead concentration $10 \mu \mathrm{g} / 100 \mathrm{~g}$ ) was incubated with lead acetate $(60 \mu \mathrm{g} / 100 \mathrm{ml})$ to induce ALA-D inhibition by method previously reported. ' Half the lysate lead-loaded was treated with zinc and DTT as described in materials and methods $(------)$, to the other half distilled water was added instead of zinc and DTT (- $)$.

Table 2 ALA-D activity and blood lead concentrations of subjects examined in fig 2

\begin{tabular}{llll}
\hline Subjects & $\begin{array}{l}\text { Blood lead } \\
\text { concentrations } \\
(\mu \mathrm{g} / 100 \mathrm{~g})\end{array}$ & ALA-D activity \\
\cline { 3 - 4 } & 10 & Unit $^{*}$ & $A_{\text {sss }}$ \\
\hline (a) & 10 & 49.9 & \\
(b) & 53 & 15.3 & \\
(c) & 57 & 15.4 & \\
(c') without & & 0.022 \\
\multicolumn{2}{c}{ with } & & 0.218 \\
\hline
\end{tabular}

${ }^{*} \mu$ moles delta-aminolaevulinic acid/min/ml RBC. (a), (b), and (c) are the subjects examined in fig 2 . ( $\left.c^{\prime}\right)$ was erythrocyte supernatant from the subject (c), and ALA-D activity was determined with or without treatment of zinc and DTT.

Table 3 ALA-D activity of erythrocyte supernatant used for gel filtrations in fig 3

\begin{tabular}{ll}
\hline & $A L A-D$ activity $\left(A_{\text {sss }}\right)$ \\
\hline No addition of lead & 0.210 \\
Plus lead & 0.015 \\
Plus lead plus zinc and DTT & 0.145 \\
\hline
\end{tabular}

has been bound in vivo (fig 2) and in vitro (fig 3) accompanies the restoration of ALA-D inhibition (tables 2 and 3 ).

A Sephadex G-75 column was used to make a rough estimation of the molecular weight of the lead peak that appeared after the addition of zinc and DTT (fig 4). Lead removed from the proteins is eluted together with DTT and is found in an elution volume encompassed by a Ve/Vo of 3.0. The lead eluted together with DTT seems not to be protein bound.

From these experiments we have been able to show the nature of ALA-D inhibition by lead at low concentrations and its restoration by heating, zinc, or DTT or both. We have also examined whether the nature of ALA-D inhibition is specific to lead. In the presence or absence of the $\mathrm{Hb}$ fraction, the ALA-D fraction was preincubated at $4^{\circ} \mathrm{C}$ for 20 hours with the chlorides of various heavy metals (table 4). In the absence of the $\mathrm{Hb}$ fraction, $\mathrm{Cu}^{++}$, $\mathrm{Hg}^{++}$, methylmercury, and $\mathrm{Cd}^{++}$powerfully inhibit the activity of ALA-D whereas the presence of the $\mathrm{Hb}$ fraction decreases the extent of inhibition by these metals. The inhibition is not restored by heat treatment and this differs from the inhibition produced by lead. The inhibition by $\mathrm{Sn}^{++}$is similar to that of lead because it increases in the presence of

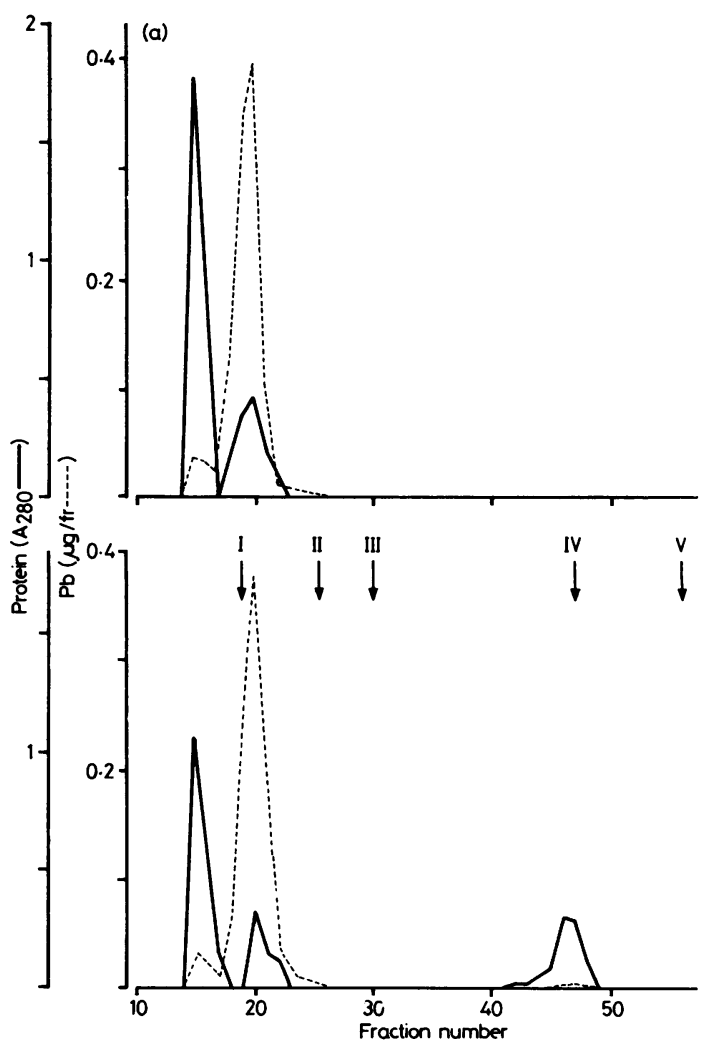

Fig 4 Form of lead removed from high molecular weight proteins by zinc and DTT. Erythrocyte lysate from a lead worker was gel filtrated by Sephadex G-75 column with (b) or without (a) the treatment of zinc and DTT.

Concentrations of lead in blood, zinc protoporphyrin in $R B C$, and $\delta$-aminolaevulinic acid and coproporphyrin in urine of the subject were $48 \mu \mathrm{g} / 100 \mathrm{~g}, 233 \mu \mathrm{g} / 100 \mathrm{ml}, 11.8$ $\mathrm{mg} / 100 \mathrm{ml}$, and $149 \mu \mathrm{g} / 1$ respectively. Proteins with known-molecular weight, DTT, and amino-acid were also gel filtrated by the same column: I ovalbumin (45 000), II chymotrypsinogen (25 000), III cytochrome C (12 500), IV $D T T$, and $V$ tryptophane. 
Table $4 A L A-D$ inhibition by various metals and its restoration by heat, DTT, or zinc

\begin{tabular}{|c|c|c|c|c|c|}
\hline \multirow[t]{3}{*}{ Metal ions } & \multicolumn{5}{|c|}{$A L A-D$ activity $\left(A_{s s s}\right)$} \\
\hline & \multirow[t]{2}{*}{ Enzyme alone } & \multicolumn{4}{|c|}{ Enzyme plus $\mathrm{Hb}$ fraction } \\
\hline & & $\begin{array}{l}\text { No further } \\
\text { treatment }\end{array}$ & Heat & $D T T$ & Zinc \\
\hline $\begin{array}{l}\text { Control } \\
\mathrm{Cu}+\left(10^{-7} \mathrm{M}\right) \\
\\
\mathrm{Pb}+\left(10^{-6} \mathrm{M}\right) \\
\mathrm{Sn}^{++}\left(10^{-7} \mathrm{M}\right) \\
\\
\mathrm{Hg}^{+}\left(10^{-6} \mathrm{M}\right) \\
\text { Methylmercury }\end{array}$ & $\begin{array}{l}0 \cdot 315 \\
0 \cdot 087 \\
0 \cdot 012 \\
0 \cdot 300 \\
0 \cdot 303 \\
0 \cdot 320 \\
0 \cdot 010\end{array}$ & $\begin{array}{l}0.249 \\
0.255 \\
0 \cdot 194 \\
0 \cdot 050 \\
0.256 \\
0.165 \\
0.020\end{array}$ & $\begin{array}{l}0.281 \\
0 \cdot 148 \\
0.092 \\
0 \cdot 180 \\
0.283 \\
0.275 \\
0.012\end{array}$ & $\begin{array}{l}0.333 \\
0.332 \\
0.310 \\
0.260 \\
0.322 \\
0.332 \\
0.344\end{array}$ & $\begin{array}{l}0.257 \\
0 \cdot 252 \\
0 \cdot 226 \\
0 \cdot 253 \\
0 \cdot 260 \\
0 \cdot 260 \\
0 \cdot 035\end{array}$ \\
\hline $\mathrm{Cd}++\left(\begin{array}{c}10^{-5} \mathrm{M} \\
\left.10^{-6} \mathrm{M}\right)\end{array}\right)$ & $\begin{array}{l}0.010 \\
0.095\end{array}$ & $\begin{array}{l}0 \cdot 180 \\
0 \cdot 140\end{array}$ & $\begin{array}{l}0.233 \\
0.035\end{array}$ & $\begin{array}{l}0.348 \\
0.273\end{array}$ & $\begin{array}{l}0 \cdot 270 \\
0 \cdot 107\end{array}$ \\
\hline
\end{tabular}

Heat $\left(60^{\circ} \mathrm{C}, 5 \mathrm{~min}\right)$, DTT $(10 \mathrm{mM})$, and zinc $(100 \mu \mathrm{M})$.

$\mathrm{Hb}$ fraction and is partly restored by heating. The inhibition concentration of tin, however, is over 10-fold higher than that of lead. The inhibition by methylmercury is partly restored by zinc, but the $\mathrm{Hb}$ fraction does not intensify the inhibition. The addition of DTT to the reaction mixture non-specifically restores the inhibition by all the metals examined.

\section{Discussion}

The results presented here support and confirm our working hypothesis on the mechanisms of the ALA-D inhibition by lead at low concentrations. ${ }^{2}$ The extent of ALA-D inhibition with the Hb fraction (factors) first-preincubated with lead was almost identical to that of the inhibition of ALA-D first-preincubated with lead (fig 1). This observation is consistent with that previously reported. ${ }^{1}$ Lead added to the erythrocyte lysate from normal subjects is found mainly in the Hb fraction and ALA-D activity is not inhibited. When the lysate is further incubated the lead is transferred to the ALA-D fraction proteins and the activity is significantly inhibited. In the isolated ALA-D fraction where lead is bound to proteins, however, ALA-D inhibition is not found. If the fraction is incubated with the $\mathrm{Hb}$ fraction (factors) for 20-40 hours, there is a pronounced inhibition of the activity of ALA-D. Based on the present data, and the previous findings, ${ }^{1}$ ternary complex of ALA-D (E), lead (Pb) and factors (F) is probably formed during the preincubation. The complex might be the non-active form of the enzyme. There was no change in the $\mathrm{Km}$ values of the enzyme incubated with the $\mathrm{Hb}$ fraction in the presence or absence of lead acetate (table 1), indicating that lead incorporated into the complex does not affect the affinity of ALA-D for substrate. Thus the ternary complex can bind the substrate, but cannot dissociate the product (porphobilinogen).
Whether lead in the complex interferes with the process of the condensation of two moles of $\delta$-aminolevulinic acid remains to be investigated. The restoration of inhibited activity by gel filtration ${ }^{3}$ is probably due to the dissociation of the complex.

In another paper $^{2}$ we have discussed the mechanisms of restoring ALA-D inhibition by heating, and the differences between the action of zinc or DTT, or both, and of heating. The present data from the restoration experiments (figs $2-4$ ) indicate that the recovery of activity correlates well with the removal of lead from the ALA-D fraction proteins. The removal of lead would result in the dissociation of the ternary complex, restoring the activity. From the present findings alone it is not clear whether the zinc, added with DTT, is incorporated into the high affinity sites on the ALA-D molecules instead of lead. ${ }^{2}$ Zinc, however, is required for the enzyme to become active, and 4-g atoms of zinc are bound to the octameric enzyme to produce maximum activity when the essential sulphydryl groups are in the reduced state. ${ }^{25}$

The lead removed from the high molecular weight proteins was eluted with DTT and seemed not to bind proteins (fig 4). In the classification of erythrocyte lead by Raghavan et $a^{26}$ the removed lead is free because the elution volume by Sephadex G-75 extends to a $\mathrm{Ve} / \mathrm{Vo}$ of 3.0. The lead is either in an inorganic form or bound to amino-acids or small peptides; this point requires further investigation. Raghavan $e t a^{26}$ also reported the induction of a 10000 molecular weight protein in lead-exposed workers that has the function of detoxifying erythrocyte lead. As shown in fig 4, we failed to detect this protein-bound lead. This failure might be due to the appearance of toxicity in the subject who showed moderately high levels of blood zinc protoporphyrin, urinary $\delta$-aminolaevulinic acid, and coproporphyrin. 
The inhibitory action of tin on ALA-D activity was similar to that by lead and the inhibition by tin is restored by heat; the inhibitory concentrations of tin were 10-fold higher than those of lead, however (table 4). The blood tin concentration $(6 \mu$ moles in total blood) is of the same order as the blood lead concentration ( $7 \mu$ moles in total blood) in man, ${ }^{27}$ but no relationship between blood tin concentrations and ALA-D activity has so far been shown.

From our results we conclude that the recovery of the activity of ALA-D by heat is the most specific measure by which to detect exposure to lead.

\section{References}

' Sakai T, Yanagihara S, Kunugi Y, Ushio K. Relationships between distribution of lead in erythrocytes in vivo and in vitro, and inhibition of ALA-D. Br J Ind Med 1982;39:382-7.

${ }^{2}$ Sakai T, Yanagihara S, Ushio K. Erythrocyte factors concerned in the inhibition of ALA-D by lead. $\mathrm{Br} J$ Ind Med 1981;38:268-74.

${ }^{3}$ Vergnano C, Cartasegna C, Ardoino V. Mechanisms of erythrocytic $\delta$-aminolevulinic acid (ALA) dehydratase inhibition in human and experimental lead-poisoning. Med Lav 1969;60:505-16.

${ }^{4}$ Candura F, Franco G, Pozzi U. Influence of heat on the ALAdehydratasic erythrocytic activity in the rabbit and in the man. I Investigations on lead-intoxication. Lav Um 1971;23:1-10.

${ }^{5}$ Haas T, Mache W, Schaller K-H, Mache K, Klavis G, Stumpf R. The determination of delta-aminolaevulinic acid dehydratase activity and its diagnostic value. Internaationales Archiv fur Arbeitsmedizin 1972;30:87-104.

${ }^{6}$ Hapke H-J, Prigge E. Interactions of lead and glutathione with delta-aminolevulinic acid dehydratase. Arch Toxicol 1973;31:153-61.

${ }^{7}$ Finelli VN, Klauder DS, Karaffa MA, Petering HG. Interaction of zinc and lead on $\delta$-aminolevulinate dehydratase. Biochem Biophys Res Commun 1975;65:303-11.

${ }^{8}$ Schlipkoter H-W, Ghelerter L, Ost B. Untersuchungen zur Kombinationswirkung von Zink und Blei. Zentralblatt für Bakteriologie und Hygiene 1975;160:130-8.

${ }^{9}$ Granick JL, Sassa S, Granick S, Levere RD, Kappas A. Studies in lead poisoning. II Correlation between the ratio of activated $\delta$-aminolevulinic acid dehydratase of whole blood and the blood lead level. Biochem Med 1973;8:149-59.

${ }^{10}$ Ushio K, Sakai T, Yanagihara S, Watanabe H. Properties of ALA-D ( $\delta$-aminolevulinic acid dehydratase) and the evaluation of lead exposure using heat activation. Jap $J$ Ind Health 1975;17:475-82.
"Tomokuni K, Kawanishi T. Relationship between activation of delta-aminolevulinic acid dehydratase by heating and blood lead level. Arch Toxicol 1975;34:253-8.

${ }^{12}$ Chiba M. Activity of erythrocyte $\delta$-aminolaevulinic acid dehydratase and its change by heat treatment as indices of lead exposure. Br J Ind Med 1976;33;36-42.

${ }^{13}$ Mitchell RA, Drake JE, Wittlin LA, Rejent TA. Erythrocyte porphobilinogen synthase (delta-aminolevulinate dehydratase) activity: a reliable and quantitative indicator of lead exposure in humans. Clin Chem 1977;23:105-11.

${ }^{14}$ Sakai T, Yanagihara S, Ushio K. Effect of metal ions on ALA-D activity in vitro and evaluation of lead-burden by zinc activation of ALA-D. Journal of Japan Accident Medical Association 1979;27:30-8.

is Sakai T, Yanagihara S, Ushio K. Restoration of lead-inhibited 5-aminolevulinate dehydratase activity in whole blood by heat, zinc ion, and (or) dithiothreitol. Clin Chem 1980;26:625-8.

${ }^{16}$ Trevisan A, Chinello V, Buzzo A, Gori GP. Postulated mode of action of lead of aminolevulinic acid dehydratase in chronic exposure. Int Arch Occup Environ Health 1981;48:295-300.

${ }^{17}$ Lauwerys RR, Buchet J-P, Roels HA. Comparative study of effect of inorganic lead and cadmium on blood $\delta$-aminolaevulinate dehydratase in man. $\mathrm{Br} J$ Ind Med 1973;30:359-64.

${ }^{18}$ Schutz A, Skerfving S. Blood cell $\delta$-aminolevulinic acid dehydratase activity in humans exposed to methylmercury. Scand $J$ Work Environ Health 1975;1:54-9.

${ }^{19}$ Chiba M, Kikuchi M. 5-aminolaevulinate dehydratase activity in blood of rabbits given tin or lead. Br J Ind Med 1979;36:3235.

${ }^{20}$ Calissano P, Cartasegna C, Bonsignore D. On the action of some metals on the erythrocytary ALA-dehydratase purified from human blood. Lav Um 1965;17:493-7.

${ }^{21}$ Thompson J, Jones DD, Beasley WH. The effect of metal ions on the activity of $\delta$-aminolaevulinic acid dehydratase. $\mathrm{Br} \mathrm{J}$ Ind Med 1977;34:32-6.

${ }^{22}$ Tomokuni $\mathrm{K}$. The in vitro effect of metal ions on the activity of erythrocyte $\delta$-aminolevulinic acid dehydratase. Jap $J$ Ind Health 1979;21:240-5.

${ }^{23}$ Haeger-Aronsen B, Schutz A. Antagonistic effect in vivo of zinc on inhibition of $\delta$-aminolevulinic acid dehydratase by lead. Arch Environ Health 1976;31:215-20.

${ }^{24}$ Abdulla M, Svensson S, Haeger-Aronsen B. Antagonistic effect of zinc and aluminum on lead inhibition of $\delta$-aminolevulinic acid dehydratase. Arch Environ Health 1979;34:464-9.

${ }^{25}$ Meredith PA, Moore MR. The in vivo effects of zinc on erythrocyte delta-aminolaevulinic acid dehydratase in man. Int Arch Occup Environ Health 1980;45:163-8.

${ }^{26}$ Raghavan SRV, Culver BD, Gonick HC. Erythrocyte leadbinding protein after occupational exposure. I Relationship to lead toxicity. Environ Res 1980;22:264-70.

${ }^{27}$ Schroeder HA, Nason AP. Trace-element analysis in clinica chemistry. Clin Chem 1971;17:461-74. 